BMJ Open

Diabetes

Research

\& Care

\section{Impact of New York State's Health Home program on access to care among patients with diabetes}

\author{
Victoria Mayer, ${ }^{1,2}$ Tod Mijanovich, ${ }^{3}$ Natalia Egorova, ${ }^{1}$ James Flory, ${ }^{4}$ Alvin Mushlin, ${ }^{5}$ \\ Michele Calvo, ${ }^{6}$ Richa Deshpande, ${ }^{1,7}$ David Siscovick ${ }^{6}$
}

To cite: Mayer V, Mijanovich T, Egorova N, et al. Impact of New York State's Health Home program on access to care among patients with diabetes. BMJ Open Diab Res Care 2021;9:e002204. doi:10.1136/ bmjdrc-2021-002204

- Additional supplemental material is published online only. To view, please visit the journal online (http://dx.doi. org/10.1136/bmjdrc-2021002204).

Received 9 March 2021 Accepted 4 July 2021
Check for updates

(c) Author(s) (or their employer(s)) 2021. Re-use permitted under CC BY-NC. No commercial re-use. See rights and permissions. Published by BMJ.

For numbered affiliations see end of article.

Correspondence to Dr Victoria Mayer; victoria.mayer@mountsinai.org

\section{ABSTRACT}

Introduction Access to care is essential for patients with diabetes to maintain health and prevent complications, and is important for health equity. New York State's Health Homes (HHs) provide care management services to Medicaid-insured patients with chronic conditions, including diabetes, and aim to improve quality of care and outcomes. There is inconsistent evidence on the impact of $\mathrm{HHs}$, and care management programs more broadly, on access to care.

Research design and methods Using a cohort of patients with diabetes derived from electronic health records from the INSIGHT Clinical Research Network, we analyzed Medicaid data for $\mathrm{HH}$ enrollees and a matched comparison group of $\mathrm{HH}$ non-enrollees. We estimated $\mathrm{HH}$ impacts on several access measures using natural experiment methods.

Results We identified and matched $11646 \mathrm{HH}$ enrollees; patients were largely non-Hispanic Black (29.9\%) and Hispanic (48.7\%), and had high rates of dual eligibility (33.0\%), Supplemental Security Income disability enrollment (49.1\%), and multiple comorbidities. In the 12 months following $\mathrm{HH}$ enrollment, $\mathrm{HH}$ enrollees had one more month of Medicaid coverage $(p<0.001)$ and 4.6 more outpatient visits than expected ( $p<0.001$, evenly distributed between primary and specialty care). There were also positive impacts on the proportions of patients with follow-up visits within 7 days (4 percentage points $(p p), p<0.001)$ and 30 days $(6 p p, p<0.001)$ after inpatient care, and on the proportion of patients with follow-up visits within 30 days after emergency department (ED) care $(4 p p, p<0.001)$. We did not find meaningful differences in continuity of care. We found small positive impacts on the proportion of patients with an inpatient visit and the proportion with an ED visit.

Conclusions New York State's HH program improved access to care for Medicaid recipients with diabetes. These findings have implications for New York State Medicaid as well as other providers and care management programs.

\section{INTRODUCTION}

Access to care is an important determinant of health, disease status, and equity. ${ }^{12}$ Access to specialty care visits, along with primary care visits, has been linked to greater receipt of guideline concordant care and better functional outcomes. ${ }^{34}$ Some evidence indicates

\section{Significance of this study}

What is already known about this subject?

- Care management programs have not been found to impact hospital admissions, but there is inconsistent evidence of an effect on primary care (outpatient) services or other measures of access.

What are the new findings?

- New York State Medicaid's Health Home program was associated with significant increases in access to care among patients with diabetes:

In the 12 months following $\mathrm{HH}$ enrollment, $\mathrm{HH}$ enrollees had 1 more month of Medicaid coverage $(p<0.001)$ than expected.

In the 12 months following $\mathrm{HH}$ enrollment, $\mathrm{HH}$ enrollees had 4.6 more outpatient visits than expected $(p<0.001$, evenly distributed between primary and specialty care).

There were also positive impacts on the proportions of patients with follow-up visits within 7 days $(4$ percentage points $(p p), p<0.001$ ) and 30 days ( $6 p p, p<0.001)$ after inpatient care, and on the proportion of patients with follow-up visits within 30 days after emergency department care $(4 p p, p<0.001)$.

How might these results change the focus of research or clinical practice?

- These findings can inform future research that examines the impact of care management programs on access to care, a rarely studied, but patient-centered set of outcomes relevant to achieving health equity.

- In addition, the findings suggest future analyses should examine the clinical significance of observed differences in access to care measures.

that access to prompt (within 7 days) postdischarge follow-up primary care visits have been associated with fewer 30-day readmissions to the hospital. ${ }^{5-8}$ Continuity of primary care, an aspect of access to care, has been associated with fewer hospitalizations and emergency room visits, lower costs, better patient satisfaction, and lower mortality. ${ }^{9-15}$ Due to systemic inequity in the USA, Black and Latinx individuals, people with low income, and those with 
certain chronic illnesses and disabilities have inadequate access to care. ${ }^{21617}$

For patients with diabetes, having health insurance coverage and adequate access to necessary and timely health services is essential for managing their illness and preventing complications. ${ }^{18-20}$ Access has been associated with quality and outcomes of care among patients with diabetes including glycemic and other risk factor control, rates of screenings for kidney, eye, and foot complications, prompt care for acute and chronic illnesses, timely specialty referrals, and complications. ${ }^{321-26}$

The principal goal of care management programs is to improve access to and coordination of care. As part of the Patient Protection and Affordable Care Act of 2010, 'health homes' (HHs) were authorized and funded to manage and coordinate care for individuals enrolled in Medicaid with complex chronic conditions. ${ }^{27}$ Diabetes was one of the conditions prioritized for $\mathrm{HH}$ enrollment. Six services are eligible for reimbursement through the HH program: comprehensive care management, care coordination and health promotion, comprehensive transitional care assistance, patient and family support, referral to community and social support services, and use of health information technology to link services. ${ }^{28}$ New York State established its Medicaid Health Home program in 2011; eligible individuals include people living with HIV, those with serious mental illness, or those with two or more chronic conditions. ${ }^{29}$ Through coordination of care, intensive case management, and attention to social needs, the program intends to help individuals with diabetes and other conditions establish more steady relationships with primary healthcare teams, gain greater access to outpatient services, and improve transitions between care sites. Qualitative information collected previously from our study indicates that $\mathrm{HH}$ members view assistance with accessing care to be one of the most desired and valuable services provided by their care managers. ${ }^{30}$

While improving access to care is recognized and important, especially for underserved populations and for those with diabetes, the evidence of a beneficial impact of care management programs is sparse, especially among those with complex needs. The implementation of the HH program in some, but not all eligible patients with diabetes, presents a 'natural experiment' through which to study these impacts, as a goal of the $\mathrm{HH}$ program is to assure that patients get the care they need when they need it. Therefore, in this analysis, we sought to determine the effect of $\mathrm{HH}$ enrollment on access to care for patients with diabetes and other chronic conditions by examining the number of outpatient visits (both primary care and specialty care), ED visits, and hospitalizations, transitions in care, continuity of care (COC), and Medicaid coverage in the 12 months prior to enrollment compared with the 12 months post enrollment in $\mathrm{HH}$ members compared with a matched comparison group of Medicaid-insured patients with diabetes who did not enroll in the $\mathrm{HH}$.

\section{METHODS}

\section{Study population, data sources, and setting}

We derived our sample from the INSIGHT Clinical Research Network electronic health record (EHR) data from six large healthcare systems in New York City. ${ }^{31}$ The cohort included individuals who met modified SUrveillance, PREvention, and ManagemEment of Diabetes Mellitus (SUPREME-DM) ${ }^{32}$ criteria for diabetes (diagnosis, laboratory, and/or medication criteria) between 2010 and 2016, were insured by Medicaid, and were over 18 years of age as of January 1, 2010. Additional Medicaid $\mathrm{HH}$ program data were then used to identify $\mathrm{HH}$ enrollees and their periods of enrollment. Access to care data for this study was derived from fee-for-service claims and managed care encounter records from the New York State Department of Health for calendar years 2010-2017.

\section{Study groups}

Individuals need to consent to enroll in an $\mathrm{HH}$; they are not automatically a part of the program, even if they are eligible. HH programs received reimbursement for outreach to eligible individuals for up to a 3-month period prior to enrollment, though some $\mathrm{HH}$ participants enrolled directly. We defined our $\mathrm{HH}$ enrollee group ('program group') as any individual with at least 1 month of HH enrollment $(n=11646)$. Our matched comparison group included individuals who never enrolled in an $\mathrm{HH}$; this includes individuals who received outreach but did not ultimately enroll $(\mathrm{n}=10640)$, as well as individuals who did not receive any outreach $(\mathrm{n}=15$ 961). This does not mean, however, that outreached individuals declined $\mathrm{HH}$ services. In fact, non-enrollment despite outreach was frequently attributed to difficulties in contacting individuals, often due to a lack of up-todate contact information. ${ }^{28}$

We defined a 12-month 'baseline' period immediately predating, and a 12-month 'follow-up' period immediately postdating, an 'index $\mathrm{HH}$ activation date'. For the program group, this index date was the earliest date of outreach by or enrollment in an HH. For comparison group members in the outreach group who never enrolled in an $\mathrm{HH}$, the index date was the earliest date of outreach. For each potential comparison group member who received neither outreach nor enrollment, we randomly selected one index date in 2011-2016, with a probability corresponding to the frequency distribution of the number of Medicaid enrolled months in the baseline periods of program group members. For example, if $90 \%$ of program group members were enrolled in Medicaid in all 12 baseline period months, comparison group index dates immediately preceded by 12 enrolled months in Medicaid had a $90 \%$ probability of being selected. We then conducted 5:1 matching with replacement using both the outreached but never enrolled group and the selected dates from the never outreached or enrolled group (see below for details on matching methods). 
As Medicaid data were available for calendar years 2010-2017, Medicaid recipients whose HH index date occurred in calendar years 2011-2016 and who were subsequently enrolled were included in the program group to allow for complete observation of Medicaid utilization for 1 year before, and 1 year after, their index date.

\section{Measures}

Several sociodemographic and health services characteristics including age, gender, race/ethnicity, receipt of Medicare (dual-eligible status), receipt of Supplemental Security Income (SSI), and Medicaid enrollment in each calendar month were directly derived from Medicaid enrollment and eligibility data. Care utilization was measured in separate categories of services using procedure and rate codes, place and category of service, and provider specialty on claim (in the case of fee-for-service) or encounter (in the case of managed care) records. Diagnoses on claims or encounters were used to create indicators for the presence of several disease conditions in the baseline period.

We used the Agency for Healthcare Research and Quality's Healthcare Cost and Utilization Project (HCUP) Clinical Classification Software (CCS) programs applied to International Classification of Diseases (ICD) diagnoses on claims to create indicators of any cancer (CCS 11-36, exclude 22), serious mental illness (CCS 657, $658,659,662)$, substance use disorders (CCS 660, 661), HIV (CCS 5, 9), and diabetes (CCS 49, 50). ${ }^{33}$ Diabetes diagnoses were further categorized into separate indicators for a diagnosis received in an inpatient setting or an outpatient setting. A count of chronic conditions was created using the HCUP chronic condition indicator (CCI). ${ }^{34}$

Care access measures included:

- Outpatient utilization: Counts of primary care visits (defined as office visits with primary care, internal medicine, or family practice provider specialties) and specialty care visits (defined as all other specialties except for psychiatry), and total outpatient visits as the sum of the two.

- Medicaid enrollment: The number of months enrolled in Medicaid.

- Transitions in care measures (recorded as missing value for individuals without an inpatient stay, or without an emergency department (ED) visit, in the relevant (baseline or follow-up) period), as follows:

- The proportion of an individual's inpatient stays followed by an outpatient visit within 7 days, and within 30 days, of discharge.

- The proportion of an individual's ED visits followed by an outpatient visit within 7 days, and within 30 days, of the ED visit.

- Continuity of care:

- The Bice-Boxerman COC Index for the baseline or follow-up period, which is a claims-based measure of the degree to which a patient's visits over a time period or illness are dispersed among a single or multiple providers. ${ }^{35} 36$

- The Usual Provider of Care (UPC) Index for the baseline or follow-up period, which is a claimsbased measure of the concentration of care with a single, primary provider. ${ }^{35}$

- The proportion of individuals with at least one inpatient stay.

- The proportion of individuals with at least one ED visit.

\section{Matching and weighting}

Our matching procedure first identified the five "nearest neighbors' for each program group member 'with replacement' using Mahalanobis distance as the distance metric. ${ }^{37}$ An entropy balance weight was then calculated in order to estimate the average effect of treatment on the treated. Entropy balance weights generalize the 'synthetic control method' to include multiple treated cases, and have been shown to achieve near perfect covariate balance. $^{38}$

Matching variables included all demographic and baseline period utilization measures described in the 'Measures' section above, as well as total Medicaid payments recorded in the claims and encounter data. In order to match on the utilization time trend, total Medicaid cost was matched for each calendar month in the baseline period. This combination of matching on time invariant characteristics such as demographics, and matching on repeated measures that capture the time trend, reduces confounding introduced by 'differential mean reversion' between the treated and comparison groups, by which an estimated treatment 'effect' may be an artifact of different rates of regression to the mean due to unobserved differences between the groups. ${ }^{39}$

The COC indices (UPC and COC) were also measured in the baseline period and used as matching variables, but because UPC is undefined for individuals with no visits, and COC is undefined for individuals with fewer than two visits, these measures were set to zero when undefined, and a missing indicator for each measure was included in the matching procedure, in order to retain individuals with few or no outpatient visits in the baseline period.

\section{Statistical analysis}

In order to estimate the HH program's impact on access and COC in the 12-month follow-up period, regression models were estimated of the form:

Outcome $_{i t}=\beta_{0}+\beta_{1}$ Enrolled $_{\mathrm{i}}+\beta_{2}$ Outcome $_{\mathrm{i}(\mathrm{t}-1)}+\gamma \mathrm{X}_{\mathrm{i}}+\mathrm{e}_{\mathrm{i}}$, where Outcome $\mathrm{i}_{\mathrm{i}(\mathrm{t}-1)}$ represents the level of the outcome during the baseline period, and $\mathrm{X}_{\mathrm{i}}$ represents a vector of covariates including additional baseline inpatient and outpatient utilization measures and sociodemographic characteristics. Additional impact models were estimated while also adjusting for the number of months of Medicaid enrollment in the follow-up period, in order to determine the extent to which estimated program effects were dependent on the program's effect on Medicaid 
enrollment. Because maintaining Medicaid enrollment can be an important tool for maintaining access to care, our main results do not adjust for Medicaid enrollment in the follow-up period, but we include enrollment-adjusted results in an online supplemental table. Enrolled is an indicator of $\mathrm{HH}$ enrollment, thus the main quantity of interest is $\beta_{1}$, which represents the estimated impact of enrollment on the outcome. Including a lagged outcome measured in the baseline period as a regressor enables us to control for the comparison group pre-to-post change within a difference-in-differences framework. All models used entropy balance weights as probability weights, and robust standard errors were estimated.

Fractional logistic regression models were estimated for outcomes whose values ranged from 0 to 1 (COC and UPC measures, and the proportion of hospitalizations or ED visits followed up within 7 , or 30 , days by an outpatient visit). Logistic regression models were estimated for the presence of any hospitalization or any ED visit in the follow-up period. Negative binomial models were estimated for the number of primary care, specialty care, and total outpatient (primary care plus specialty care) visits.

Because the 7/30-day follow-up measures are only defined for individuals experiencing an 'index' event (either a hospitalization or and ED visit), and the COC and UPC measures are only defined for individuals having at least two, or at least one, outpatient visit, respectively, these models were estimated only on individuals meeting these criteria in the follow-up period. In order to retain all such individuals in the models, missing baseline COC and UPC indices and follow-up measures for the baseline period were set to zero and missing indicators were included for each of these when used as baseline period covariates.

Since the COC and UPG indices are difficult to interpret, Cohen's $d$ effect sizes were calculated for all impacts. ${ }^{40}$ For logistic regression results, log-odds were converted to Cohen's $d$ using the formula: $\mathrm{d}=\log (\mathrm{OR}) *$ $\operatorname{sqrt}(3) /$ pi. $^{41}$

\section{RESULTS}

We identified 115434 individuals with diabetes using the INSIGHT EHR data. Table 1 presents the baseline characteristics for the 11646 individuals who enrolled in an HH in 2010-2016. A sizeable percentage of HH enrollees were non-Hispanic Black (29.9\%) or Hispanic (48.7\%) individuals; $33.0 \%$ were dual-eligible, and $49.1 \%$ received SSI disability. As expected, this population had complex needs indicated by multiple comorbidities, including $53.7 \%$ with serious mental illness, $26.9 \%$ with alcohol and substance use disorders, and a mean of $17.0 \mathrm{CCI}$ conditions. In the baseline period, the group had high rates of healthcare utilization (mean of 1.0 hospitalization, 1.1 ED visits) and Medicaid payments (mean $\$ 45$ 488 in nominal dollars).

Tables 2 and 3 display the results of our matching and weighting procedures. After matching and weighting,
Table 1 Characteristics of health home enrollees in the 12-month baseline period before enrollment

\begin{tabular}{|c|c|}
\hline Measure & $\begin{array}{l}\mathrm{N}(\%) \text {, mean (SD), or } \\
\text { median (range) } \\
\mathrm{n}=11646\end{array}$ \\
\hline Medicare & $3841(33.0 \%)$ \\
\hline SSI due to disability & $5720(49.1 \%)$ \\
\hline SSI due to age & $2344(20.1 \%)$ \\
\hline Female & $6999(60.0 \%)$ \\
\hline \multicolumn{2}{|l|}{ Age } \\
\hline Mean (SD) & $55.2(12.6)$ \\
\hline Median (range) & $56(18-98)$ \\
\hline \multicolumn{2}{|l|}{ Age category (years) } \\
\hline $15-44$ & $1986(17.0 \%)$ \\
\hline $45-64$ & $7287(62.5 \%)$ \\
\hline $65+$ & $2383(20.4 \%)$ \\
\hline \multicolumn{2}{|l|}{ Race and ethnicity } \\
\hline Hispanic & $5674(48.7 \%)$ \\
\hline Non-Hispanic Black & $3488(29.9 \%)$ \\
\hline Non-Hispanic white & $1228(10.5 \%)$ \\
\hline Other/unknown & $1266(10.9 \%)$ \\
\hline \multicolumn{2}{|l|}{ Months of Medicaid enrollment } \\
\hline Mean (SD) & $11.6(1.5)$ \\
\hline Median (range) & $12(2-12)$ \\
\hline Any inpatient diabetes diagnosis & $3697(31.7 \%)$ \\
\hline Any outpatient diabetes diagnosis & $8165(70.0 \%)$ \\
\hline Serious mental illness diagnosis & $6254(53.7 \%)$ \\
\hline $\begin{array}{l}\text { Alcohol or substance use disorder } \\
\text { diagnosis }\end{array}$ & $3136(26.9 \%)$ \\
\hline Cancer diagnosis & $1831(15.7 \%)$ \\
\hline HIV diagnosis & $3699(31.7 \%)$ \\
\hline \multicolumn{2}{|l|}{ Number of chronic $(\mathrm{CCl})$ conditions } \\
\hline Mean (SD) & $17.0(9.4)$ \\
\hline Median (range) & $16(0-60)$ \\
\hline \multicolumn{2}{|l|}{ Metformin prescriptions } \\
\hline Mean (SD) & $2.7(4.3)$ \\
\hline Median (range) & $0(0-25)$ \\
\hline Any metformin prescriptions & $4215(36.2 \%)$ \\
\hline \multicolumn{2}{|l|}{ Insulin prescriptions } \\
\hline Mean (SD) & $0.5(0.8)$ \\
\hline Median (range) & $0(0-2)$ \\
\hline Any insulin prescriptions & $3050(26.2 \%)$ \\
\hline \multicolumn{2}{|l|}{ Total Medicaid payments } \\
\hline Mean (SD) & $\$ 45488$ (\$61 699) \\
\hline Median (range) & $\$ 25981$ (\$0-2694748) \\
\hline \multicolumn{2}{|l|}{ Hospitalizations } \\
\hline Mean (SD) & $1.0(2.1)$ \\
\hline Median (range) & $0(0-35)$ \\
\hline Any hospitalization & 4837 (41.5\%) \\
\hline ED visits & \\
\hline
\end{tabular}

Continued 


\section{Table 1 Continued}

\begin{tabular}{|c|c|}
\hline Measure & $\begin{array}{l}\mathrm{N}(\%), \text { mean }(\mathrm{SD}) \text {, or } \\
\text { median (range) } \\
\mathrm{n}=11646\end{array}$ \\
\hline Mean (SD) & $1.1(4.0)$ \\
\hline Median (range) & $0(0-163)$ \\
\hline Any ED visit & 4125 (35.4\%) \\
\hline \multicolumn{2}{|l|}{ Primary care visits } \\
\hline Mean (SD) & $10.1(13.8)$ \\
\hline Median (range) & $6(0-345)$ \\
\hline \multicolumn{2}{|c|}{ Specialty care visits } \\
\hline Mean (SD) & $11.2(14.7)$ \\
\hline Median (range) & $7(0-227)$ \\
\hline \multicolumn{2}{|c|}{$\begin{array}{l}\text { Proportion of inpatient stays with } \\
\text { outpatient follow-up w/in } 7 \text { days }\end{array}$} \\
\hline $\mathrm{N}$ evaluated & 4837 \\
\hline Mean (SD) & $0.5(0.4)$ \\
\hline Median (range) & $1(0-1)$ \\
\hline \multicolumn{2}{|c|}{$\begin{array}{l}\text { Proportion of inpatient stays with } \\
\text { outpatient follow-up w/in } 30 \text { days }\end{array}$} \\
\hline $\mathrm{N}$ evaluated & 4837 \\
\hline Mean (SD) & $0.8(0.4)$ \\
\hline Median (range) & $1(0-1)$ \\
\hline \multicolumn{2}{|c|}{$\begin{array}{l}\text { Proportion of ED visits with outpatient } \\
\text { follow-up w/in } 7 \text { days }\end{array}$} \\
\hline $\mathrm{N}$ evaluated & 4125 \\
\hline Mean (SD) & $0.4(0.4)$ \\
\hline Median (range) & $0(0-1)$ \\
\hline \multicolumn{2}{|c|}{$\begin{array}{l}\text { Proportion of ED visits with outpatient } \\
\text { follow-up w/in } 30 \text { days }\end{array}$} \\
\hline $\mathrm{N}$ evaluated & 4125 \\
\hline Mean (SD) & $0.7(0.4)$ \\
\hline Median (range) & $1(0-1)$ \\
\hline \multicolumn{2}{|l|}{ UPC Index } \\
\hline $\mathrm{N}$ evaluated & 9963 \\
\hline Mean (SD) & $0.7(0.2)$ \\
\hline Median (range) & $1(0-1)$ \\
\hline \multicolumn{2}{|l|}{ COC Index } \\
\hline $\mathrm{N}$ evaluated & 9063 \\
\hline Mean (SD) & $0.5(0.3)$ \\
\hline Median (range) & $0(0-1)$ \\
\hline
\end{tabular}

'Visits' were defined as the number of unique combinations of provider ID, Medicaid ID, and dates within the baseline period. $\mathrm{CCl}$, chronic condition indicator; $\mathrm{COC}$, Continuity of Care; ED, emergency department; ID, identification; Range, minimum and maximum values; SSI, Supplemental Security Income; UPC, Usual Provider of Care; w/in, within.

standardized differences between the mean values for the matched groups for all matching variables were 0 , and variance ratios were 1 (within measurement error). All HH enrollees in the unmatched sample were retained in the matched sample.
Our analyses estimated $\mathrm{HH}$ program impacts as the difference between the observed mean level of each outcome and what would have been expected based on observed levels of the outcome variable in the comparison group, adjusting for baseline covariates that included observed levels of the baseline outcome in each group (table 4). In the 12 months following HH enrollment, HH enrollees had, on average, 1.0 more month of Medicaid coverage $(\mathrm{p}<0.001)$ and 4.6 more outpatient visits than expected $(p<0.001)$. The program impact on outpatient visits was evenly distributed between primary and specialty care visits. There were also positive impacts on the proportions of patients with follow-up visits within 7 days (4 percentage points (pp), $\mathrm{p}<0.001$ ) and 30 days $(6 \mathrm{pp}, \mathrm{p}<0.001)$ after an inpatient admission, and on the proportion of patients with follow-up visits within 30 days after an $\mathrm{ED}$ visit $(4 \mathrm{pp}, \mathrm{p}<0.001)$, and a marginally statistically significant positive impact on follow-up visits within 7 days after an $\mathrm{ED}$ visit (2pp, $\mathrm{p}=0.056)$. There was a small, negative program impact on the UPC Index $(-0.02, \mathrm{p}<0.001)$, and no detectable effect on the COC Index. There were also positive impacts on the proportions of patients with an inpatient stay $(7 \mathrm{pp}, \mathrm{p}<0.001)$ or an ED visit (7pp, $\mathrm{p}<0.001)$, largely attributable to decreases in these measures in the comparison group. When adjusting for months enrolled in Medicaid in the follow-up period, we found smaller impacts on outpatient visits that remained statistically significant, smaller impacts of follow-up visits within 30 days of an inpatient admission or ED visit that remained statistically significant and similar findings with regard to UPC and COC indices (online supplemental table 1).

\section{DISCUSSION}

We examined access to care among Medicaid Health Home participants with diabetes before and after enrollment compared with a matched and weighted comparison group. Overall, being in an $\mathrm{HH}$ was associated with significant improvements in access to care. We found that $\mathrm{HH}$ enrollees had more outpatient visits (both primary care and specialty visits), prompter follow-up after ED visits and admissions, and more months of Medicaid coverage in the 12-month postenrollment period. Each of these results is plausibly clinically significant (several more outpatient visits, 2-6pp increases in prompt follow-up, and one additional month of Medicaid-insurance coverage). We found a very small negative impact on one COC measure, however, for HH enrollees compared with non-enrollees; given the small effect size $(d=-0.073)$ this effect does not seem likely to be clinically significant. We also found a higher percentage of patients with inpatient and ED visits than expected. We should note that our impact estimates were attenuated toward zero when adjusting for the increase in Medicaid coverage in the follow-up period (see online supplemental table 1), such that about half of the program's impacts on outpatient, primary, and specialty care appeared to be due to 
Table 2 Means and standardized differences before and after matching and weighting

\begin{tabular}{|c|c|c|c|c|c|c|}
\hline \multirow[b]{2}{*}{ Baseline period characteristic } & \multicolumn{3}{|c|}{ Before matching/weighting } & \multicolumn{3}{|c|}{ After matching/weighting } \\
\hline & $\begin{array}{l}\text { Treated } \\
(\mathrm{n}=11 \mathrm{646})\end{array}$ & $\begin{array}{l}\text { Untreated } \\
(73973)\end{array}$ & StdDif & $\begin{array}{l}\text { Treated } \\
(\mathrm{n}=11646)\end{array}$ & $\begin{array}{l}\text { Untreated } \\
(\mathrm{n}=26 \text { 601) }\end{array}$ & StdDif \\
\hline Medicare & 0.33 & 0.55 & -0.45 & 0.33 & 0.33 & 0.00 \\
\hline SSI disabled & 0.49 & 0.22 & 0.58 & 0.49 & 0.49 & -0.00 \\
\hline SSI aged & 0.20 & 0.43 & -0.51 & 0.20 & 0.20 & 0.00 \\
\hline Any hospitalization & 0.41 & 0.27 & 0.30 & 0.41 & 0.41 & -0.00 \\
\hline Any ED visit & 0.35 & 0.21 & 0.33 & 0.35 & 0.35 & -0.00 \\
\hline Months enrolled in Medicaid & 11.59 & 11.62 & -0.02 & 11.59 & 11.59 & -0.00 \\
\hline Age & 55.23 & 62.48 & -0.50 & 55.23 & 55.23 & 0.00 \\
\hline Inpatient diabetes $\mathrm{dx}$ & 0.32 & 0.20 & 0.26 & 0.32 & 0.32 & 0.00 \\
\hline Outpatient diabetes $\mathrm{dx}$ & 0.70 & 0.60 & 0.21 & 0.70 & 0.70 & 0.00 \\
\hline SMI dx & 0.54 & 0.30 & 0.50 & 0.54 & 0.54 & -0.00 \\
\hline SUD $d x$ & 0.27 & 0.07 & 0.53 & 0.27 & 0.27 & -0.00 \\
\hline Cancer dx & 0.16 & 0.16 & -0.00 & 0.16 & 0.16 & -0.00 \\
\hline HIV dx & 0.32 & 0.08 & 0.61 & 0.32 & 0.32 & -0.00 \\
\hline Number of $\mathrm{CCl} d x s$ & 17.02 & 12.70 & 0.45 & 17.02 & 17.02 & -0.00 \\
\hline Index month (relative to January 2010) & 19890.35 & 19905.02 & -0.03 & 19890.35 & 19890.35 & 0.00 \\
\hline Non-Hispanic white & 0.11 & 0.19 & -0.25 & 0.11 & 0.11 & 0.00 \\
\hline Non-Hispanic black & 0.30 & 0.21 & 0.20 & 0.30 & 0.30 & -0.00 \\
\hline Metformin prescriptions in months $1-6$ & 1.36 & 0.87 & 0.23 & 1.36 & 1.36 & 0.00 \\
\hline Metformin prescriptions in months $7-12$ & 1.31 & 0.84 & 0.23 & 1.31 & 1.31 & 0.00 \\
\hline Insulin prescriptions in months $1-6$ & 0.22 & 0.10 & 0.33 & 0.22 & 0.22 & 0.00 \\
\hline Insulin prescriptions in months $7-12$ & 0.24 & 0.11 & 0.35 & 0.24 & 0.24 & 0.00 \\
\hline UPC Index & 0.60 & 0.52 & 0.21 & 0.60 & 0.60 & 0.00 \\
\hline Undefined UPC Index & 0.15 & 0.31 & -0.40 & 0.15 & 0.15 & 0.00 \\
\hline COC Index & 0.39 & 0.33 & 0.16 & 0.39 & 0.39 & 0.00 \\
\hline Undefined COC Index & 0.22 & 0.40 & -0.39 & 0.22 & 0.22 & 0.00 \\
\hline Month 1 cost & 4252.78 & 3825.79 & 0.04 & 4252.78 & 4252.78 & -0.00 \\
\hline Month 2 cost & 4174.61 & 3788.27 & 0.04 & 4174.61 & 4174.61 & -0.00 \\
\hline Month 3 cost & 4099.26 & 3726.99 & 0.04 & 4099.26 & 4099.26 & -0.00 \\
\hline Month 4 cost & 3967.85 & 3695.77 & 0.03 & 3967.85 & 3967.85 & -0.00 \\
\hline Month 5 cost & 3854.96 & 3587.30 & 0.03 & 3854.96 & 3854.96 & -0.00 \\
\hline Month 6 cost & 3734.25 & 3521.57 & 0.02 & 3734.25 & 3734.25 & -0.00 \\
\hline Month 7 cost & 3572.09 & 3503.08 & 0.01 & 3572.09 & 3572.09 & -0.00 \\
\hline Month 8 cost & 3653.25 & 3415.92 & 0.03 & 3653.25 & 3653.25 & -0.00 \\
\hline Month 9 cost & 3633.43 & 3394.53 & 0.03 & 3633.43 & 3633.43 & -0.00 \\
\hline Month 10 cost & 3595.15 & 3317.48 & 0.03 & 3595.15 & 3595.15 & -0.00 \\
\hline Month 11 cost & 3420.26 & 3284.35 & 0.02 & 3420.26 & 3420.26 & -0.00 \\
\hline Month 12 cost & 3493.49 & 3286.04 & 0.02 & 3493.49 & 3493.49 & -0.00 \\
\hline Hospitalizations & 0.99 & 0.47 & 0.31 & 0.99 & 0.99 & -0.00 \\
\hline ED visits & 1.05 & 0.40 & 0.20 & 1.05 & 1.05 & -0.00 \\
\hline PCP visits & 10.12 & 6.19 & 0.32 & 10.12 & 10.12 & 0.00 \\
\hline Specialty visits & 11.16 & 8.30 & 0.19 & 11.16 & 11.16 & -0.00 \\
\hline
\end{tabular}

The 'baseline period' comprised the 12 calendar months before the calendar month that contained the index date.

Undefined UPC indices ( $<2$ visits) and undefined COC indices ( $<1$ visit) were assigned values of zero for purposes of matching/weighting.

'Visits' were defined as the number of unique combinations of provider ID, Medicaid ID, and dates within the baseline period.

$\mathrm{CCl}$, chronic condition indicator; COC, Continuity of Care; dx, International Classification of Diseases (ICD) 9/10 diagnosis; ED, emergency department; ID, identification; PCP, primary care provider; SMI, serious mental illness; SSI, Supplemental Security Income; StdDif, standardized difference; SUD, substance use disorder; UPC, Usual Provider of Care. 
Table 3 Variances and variance ratios before and after matching and weighting

\begin{tabular}{|c|c|c|c|c|c|c|}
\hline \multirow[b]{2}{*}{ Baseline period characteristic } & \multicolumn{3}{|c|}{ Before matching/weighting } & \multicolumn{3}{|c|}{ After matching/weighting } \\
\hline & $\begin{array}{l}\text { Treated } \\
(\mathrm{n}=11 \text { 646) }\end{array}$ & $\begin{array}{l}\text { Untreated } \\
(73973)\end{array}$ & Ratio & $\begin{array}{l}\text { Treated } \\
(\mathrm{n}=11 \text { 646) }\end{array}$ & $\begin{array}{l}\text { Untreated } \\
(n=26601)\end{array}$ & Ratio \\
\hline Medicare & 0.22 & 0.25 & 0.89 & 0.22 & 0.22 & 1.00 \\
\hline SSI disabled & 0.25 & 0.17 & 1.44 & 0.25 & 0.25 & 1.00 \\
\hline SSI aged & 0.16 & 0.25 & 0.65 & 0.16 & 0.16 & 1.00 \\
\hline Any hospitalization & 0.24 & 0.20 & 1.23 & 0.24 & 0.24 & 1.00 \\
\hline Any ED visit & 0.23 & 0.17 & 1.38 & 0.23 & 0.23 & 1.00 \\
\hline Months enrolled in Medicaid & 2.40 & 2.54 & 0.95 & 2.40 & 2.40 & 1.00 \\
\hline Age & 158.74 & 255.11 & 0.62 & 158.74 & 158.73 & 1.00 \\
\hline Inpatient diabetes $\mathrm{dx}$ & 0.22 & 0.16 & 1.34 & 0.22 & 0.22 & 1.00 \\
\hline Outpatient diabetes $\mathrm{dx}$ & 0.21 & 0.24 & 0.87 & 0.21 & 0.21 & 1.00 \\
\hline SMI dx & 0.25 & 0.21 & 1.19 & 0.25 & 0.25 & 1.00 \\
\hline SUD $\mathrm{dx}$ & 0.20 & 0.07 & 2.84 & 0.20 & 0.20 & 1.00 \\
\hline Cancer dx & 0.13 & 0.13 & 0.99 & 0.13 & 0.13 & 1.00 \\
\hline HIV dx & 0.22 & 0.08 & 2.86 & 0.22 & 0.22 & 1.00 \\
\hline Number of chronic dxs & 88.36 & 93.57 & 0.94 & 88.36 & 88.36 & 1.00 \\
\hline Index month (relative to January 2010) & 179320.28 & 264829.06 & 0.68 & 179320.28 & 179311.62 & 1.00 \\
\hline Non-Hispanic white & 0.09 & 0.16 & 0.61 & 0.09 & 0.09 & 1.00 \\
\hline Non-Hispanic black & 0.21 & 0.17 & 1.25 & 0.21 & 0.21 & 1.00 \\
\hline Metformin prescriptions in months $1-6$ & 5.19 & 3.76 & 1.38 & 5.19 & 5.19 & 1.00 \\
\hline Metformin prescriptions in months $7-12$ & 5.10 & 3.61 & 1.41 & 5.10 & 5.10 & 1.00 \\
\hline Insulin prescriptions in months $1-6$ & 0.17 & 0.09 & 1.87 & 0.17 & 0.17 & 1.00 \\
\hline Insulin prescriptions in months $7-12$ & 0.18 & 0.10 & 1.88 & 0.18 & 0.18 & 1.00 \\
\hline UPC Index & 0.11 & 0.16 & 0.70 & 0.11 & 0.11 & 1.00 \\
\hline Undefined UPC Index & 0.12 & 0.21 & 0.58 & 0.12 & 0.12 & 1.00 \\
\hline COC Index & 0.13 & 0.15 & 0.86 & 0.13 & 0.13 & 1.00 \\
\hline Undefined COC Index & 0.17 & 0.24 & 0.72 & 0.17 & 0.17 & 1.00 \\
\hline Month 1 cost & $1.01 e+08$ & $8.43 e+07$ & 1.19 & $1.01 e+08$ & $1.01 e+08$ & 1.00 \\
\hline Month 2 cost & $7.83 e+07$ & $9.00 e+07$ & 0.87 & $7.83 e+07$ & $7.83 e+07$ & 1.00 \\
\hline Month 3 cost & $8.05 e+07$ & $9.40 e+07$ & 0.86 & $8.05 e+07$ & $8.05 e+07$ & 1.00 \\
\hline Month 4 cost & $8.22 e+07$ & $1.13 e+08$ & 0.73 & $8.22 e+07$ & $8.22 e+07$ & 1.00 \\
\hline Month 5 cost & $7.94 e+07$ & $8.82 e+07$ & 0.90 & $7.94 e+07$ & $7.94 e+07$ & 1.00 \\
\hline Month 6 cost & $9.21 e+07$ & $1.17 e+08$ & 0.79 & $9.21 e+07$ & $9.21 e+07$ & 1.00 \\
\hline Month 7 cost & $5.63 e+07$ & $9.35 \mathrm{e}+07$ & 0.60 & $5.63 e+07$ & $5.62 \mathrm{e}+07$ & 1.00 \\
\hline Month 8 cost & $6.95 e+07$ & $1.00 e+08$ & 0.69 & $6.95 e+07$ & $6.95 e+07$ & 1.00 \\
\hline Month 9 cost & $7.66 \mathrm{e}+07$ & $8.63 e+07$ & 0.89 & $7.66 e+07$ & $7.66 \mathrm{e}+07$ & 1.00 \\
\hline Month 10 cost & $6.80 e+07$ & $6.71 e+07$ & 1.01 & $6.80 e+07$ & $6.80 e+07$ & 1.00 \\
\hline Month 11 cost & $5.88 e+07$ & $8.40 e+07$ & 0.70 & $5.88 e+07$ & $5.88 e+07$ & 1.00 \\
\hline Month 12 cost & $1.29 e+08$ & $8.63 e+07$ & 1.50 & $1.29 e+08$ & $1.29 e+08$ & 1.00 \\
\hline Hospitalizations & 4.49 & 1.25 & 3.59 & 4.49 & 4.49 & 1.00 \\
\hline ED visits & 16.37 & 4.55 & 3.60 & 16.37 & 16.37 & 1.00 \\
\hline PCP visits & 190.58 & 111.02 & 1.72 & 190.58 & 190.57 & 1.00 \\
\hline Specialty visits & 215.06 & 219.31 & 0.98 & 215.06 & 215.05 & 1.00 \\
\hline
\end{tabular}

The 'baseline period' comprised the 12 calendar months before the calendar month that contained the index date.

Undefined UPC indices ( $<2$ visits) and undefined COC indices ( $<1$ visit) were assigned values of zero for purposes of matching/weighting.

'Visits were defined as the number of unique combinations of provider ID, Medicaid ID, and dates within the baseline period.

COC, Continuity of Care; dx, International Classification of Diseases (ICD) 9/10 diagnosis; ED, emergency department; ID, identification; PCP,

primary care provider; SMI, serious mental illness; SSI, Supplemental Security Income; SUD, substance use disorder; UPC, Usual Provider of Care. 


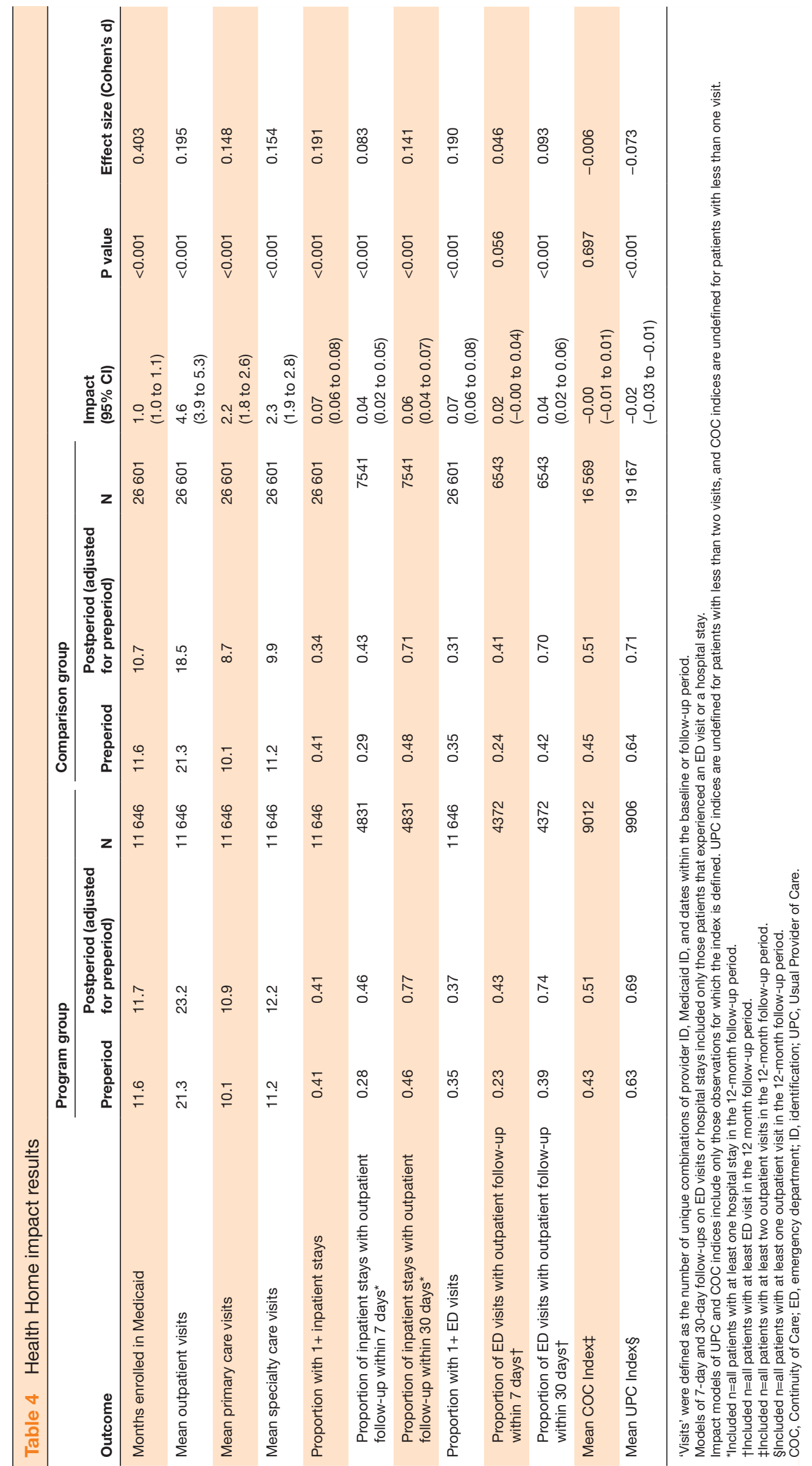


the program's impact on Medicaid enrollment, but these categories of service increased even after adjustment for longer Medicaid enrollment periods in the HH group.

Our study adds evidence about the impact of care management programs generally. While a principal goal of most care management programs is to reduce inpatient and ED utilization, and therefore costs, multiple studies, meta-analyses, and systematic reviews have found mixed effects of care management programs on healthcare utilization. ${ }^{42-49}$ An evaluation of the Chronic Illness Demonstration Project, the forerunner of the $\mathrm{HH}$ program in New York State, found a similar increase in outpatient visits. ${ }^{50}$ Most recently, Buja et al noted consistent findings across meta-analyses and systemic reviews of no impact on hospital admissions, and variable evidence of impact on ED visits, costs, length of stay, and primary care. ${ }^{49}$ But evaluations focused only on inpatient and ED utilization and costs may not capture all important impacts, especially from the patient perspective. A relatively small number of studies include outpatient care as an outcome, and these rarely evaluate other measures of access to care. In addition, very little of this research focuses on patients with complex needs. ${ }^{48}$ Therefore, our study adds to two important areas currently lacking robust evidence, namely access to care and individuals with complex needs.

Poor access to care is one reason for known disparities in diabetes care and outcomes experienced by Black and Latinx populations and those with serious mental illness. ${ }^{26}{ }^{51-54}$ Our study contributes by estimating the impact of a policy among a group largely comprised of individuals at risk for poor access because of systemic inequity (the group was $29.9 \%$ non-Hispanic Black individuals and $48.7 \%$ Hispanic individuals, and 53.7\% had a diagnosis of serious mental illness). This study also echoes the findings of our qualitative work, which found that $\mathrm{HH}$ improved access to care from the patient perspective. ${ }^{30}$

Our study has several limitations. We examined a set of intermediate markers of access to care and not clinical outcomes among patients with diabetes. Future analyses will examine whether the $\mathrm{HH}$ improved clinical outcomes including the receipt of guideline concordant care, better disease control, and fewer diabetes-related hospitalizations. The cohort we studied is a subset of patients in New York City (NYC) with diabetes who are insured by Medicaid, since it is limited to those who received at least some of their care at one of the academic medical centers that participate in the INSIGHT Clinical Research Network. As such, our sample does not represent the experience of all Medicaid-insured patients with diabetes, as patients who receive care only at NYC Health+Hospitals locations (NYC's public healthcare system) or community hospitals are not included in our cohort.

In addition, although we used advanced observational research natural experiment methods to identify and weight the comparison group, it is still possible that there were differences between the groups that we did not account for, leading to biased results. Specifically, it is possible that there were remaining unobserved differences between the groups that created 'differential mean reversion', by which individual outcome values regress to their respective population means at different rates in the two groups because the groups are drawn from fundamentally different underlying populations. ${ }^{39}$ We should note, for example, that most of our comparison group's average outcome values decrease from the baseline to the follow-up period, whereas all of the HH enrolled group's outcome values increase from baseline to follow-up. This suggests the possibility that our estimated program impacts may be biased by unobserved or unadjusted differences in illness severity that would have resulted in shorter episodes of care in the comparison cohort than in the $\mathrm{HH}$ enrolled group even in the absence of the $\mathrm{HH}$ program. As we described above, we have addressed this possibility by matching on time trends in utilization, as well as on time invariant characteristics.

This study examined data from 2010 to 2017, prior to the global pandemic of COVID-19. COVID-19 severely disrupted healthcare delivery, and thus access to care, in NYC and throughout the USA. The individuals who are members of the $\mathrm{HH}$ program are at particularly high risk for the morbidity, mortality, and care disruption caused by COVID-19. This study serves as a baseline description of access to care in a particularly vulnerable population. It suggests that for patients with diabetes and Medicaid insurance, care management services provided by the $\mathrm{HH}$ could serve an important role in connecting patients with providers and services; this connection may be even more important under pandemic circumstances, and will be a focus of our future research.

In conclusion, our results suggest that the $\mathrm{HH}$ program had a positive and favorable impact on access to care among patients with diabetes in NYC during the program's initial 5 years. These findings add to understanding the potential role that care management programs have in improving care.

\section{Author affiliations}

${ }^{1}$ Department of Population Health Science and Policy, Icahn School of Medicine at Mount Sinai, New York City, New York, USA

2Division of General Internal Medicine, Department of Medicine, Icahn School of Medicine at Mount Sinai, New York City, New York, USA

${ }^{3}$ Department of Applied Statistics, Social Sciences, and Humanities, Steinhardt School, New York University, New York City, New York, USA

${ }^{4}$ Endocrinology Service, Department of Subspecialty Medicine, Memorial Sloan Kettering Cancer Center, New York City, New York, USA

${ }^{5}$ Departments of Population Health Sciences and Medicine, Weill Cornell Medicine, New York City, New York, USA

${ }^{6}$ Research, Evaluation \& Policy, New York Academy of Medicine, New York City, New York, USA

${ }^{7}$ Center for Biostatistics, Icahn School of Medicine at Mount Sinai, New York City, New York, USA

Acknowledgements The authors thank the study's Patient/Stakeholder Advisory Board for their essential role in this work. Also, the authors would like to thank the Natural Experiments for Translation in Diabetes (NEXT-D2) research network for invaluable support and guidance throughout this study. 
Contributors VM and DS, the Principal Investigators of the study, worked with $\mathrm{TM}, \mathrm{JF}, \mathrm{AM}, \mathrm{NE}$, and RD to conceive of and design the study. TM developed the methods and conducted analyses, with input from VM, DS, JF, AM, NE, RD, and MC. All authors contributed to interpretation of results and implications. VM and DS led manuscript preparation. VM and TM drafted the manuscript; DS, JF, AM, NE, RD, and $M C$ reviewed the manuscript and contributed to substantial modifications.

Funding Research reported in this manuscript was funded through a PatientCentered Outcomes Research Institute (PCORI) Award (NEN-1508-32252), and by the PCORI Award CER-2017C3-9230 and the National Cancer Institute (P30CA008748). This work was supported by the INSIGHT Clinical Research Network, funded by the Patient-Centered Outcomes Research Institute Award, RI-CRN2020-004 (Principal Investigator: Rainu Kaushal, MD, MPH).

Disclaimer The views and opinions expressed in this report are those of the authors and do not necessarily reflect the official policy or position of the New York State Department of Health. Examples of analysis performed within this report are only examples. They should not be utilized in real-world analytic products.

Competing interests None declared.

Patient consent for publication Not required.

Ethics approval This study was approved by the Biomedical Research Alliance of New York's Institutional Review Board (BRANY, \# 16-08-299-05) with a full waiver of the requirement to obtain authorization for use or disclosure of protected health information.

Provenance and peer review Not commissioned; externally peer reviewed.

Data availability statement Data may be obtained from a third party and are not publicly available. The data that support the findings of this study are not publicly available.

Supplemental material This content has been supplied by the author(s). It has not been vetted by BMJ Publishing Group Limited (BMJ) and may not have been peer-reviewed. Any opinions or recommendations discussed are solely those of the author(s) and are not endorsed by BMJ. BMJ disclaims all liability and responsibility arising from any reliance placed on the content. Where the content includes any translated material, BMJ does not warrant the accuracy and reliability of the translations (including but not limited to local regulations, clinical guidelines, terminology, drug names and drug dosages), and is not responsible for any error and/or omissions arising from translation and adaptation or otherwise.

Open access This is an open access article distributed in accordance with the Creative Commons Attribution Non Commercial (CC BY-NC 4.0) license, which permits others to distribute, remix, adapt, build upon this work non-commercially, and license their derivative works on different terms, provided the original work is properly cited, appropriate credit is given, any changes made indicated, and the use is non-commercial. See: http://creativecommons.org/licenses/by-nc/4.0/.

\section{REFERENCES}

1 Office of Disease Prevention and Health Promotion. Healthy people 2020: access to Health Services. [Internet]. Available: https://www. healthypeople.gov/2020/topics-objectives/topic/Access-to-HealthServices [Accessed 10 Sep 2020].

2 Agency for Healthcare Research and Quality. Access and disparities in access to health care. Rockville, MD: Agency for Healthcare Research and Quality, 2016. http://www.ahrq.gov/research/findings/ nhqrdr/nhqdr15/access.html

3 Johnston KJ, Hockenberry JM. Are two heads better than one or do too many cooks spoil the broth? The trade-off between physician division of labor and patient continuity of care for older adults with complex chronic conditions. Health Serv Res 2016;51:2176-205.

4 Hostetter J, Schwarz N, Klug M, et al. Primary care visits increase utilization of evidence-based preventative health measures. BMC Fam Pract 2020;21:151.

5 Shen E, Koyama SY, Huynh DN, et al. Association of a dedicated post-hospital discharge follow-up visit and 30-day readmission risk in a Medicare Advantage population. JAMA Intern Med 2017;177:132-5.

6 Wiest D, Yang Q, Wilson C, et al. Outcomes of a citywide campaign to reduce Medicaid hospital readmissions with connection to primary care within 7 days of hospital discharge. JAMA Netw Open 2019;2:e187369.

7 Misky GJ, Wald HL, Coleman EA. Post-hospitalization transitions: examining the effects of timing of primary care provider follow-up. $J$ Hosp Med 2010;5:392-7.
8 Hernandez AF, Greiner MA, Fonarow GC, et al. Relationship between early physician follow-up and 30-day readmission among Medicare beneficiaries hospitalized for heart failure. JAMA 2010;303:1716-22.

9 Katz DA, McCoy KD, Vaughan-Sarrazin MS. Does greater continuity of Veterans Administration primary care reduce emergency department visits and hospitalization in older veterans? J Am Geriatr Soc 2015;63:2510-8.

10 van Walraven C, Oake N, Jennings A, et al. The association between continuity of care and outcomes: a systematic and critical review. $J$ Eval Clin Pract 2010;16:947-56.

11 Pourat N, Davis AC, Chen X, et al. In California, primary care continuity was associated with reduced emergency department use and fewer hospitalizations. Health Aff 2015;34:1113-20.

12 Romaire MA, Haber SG, Wensky SG, et al. Primary care and specialty providers: an assessment of continuity of care, utilization, and expenditures. Med Care 2014;52:1042-9.

13 Baker R, Freeman GK, Haggerty JL, et al. Primary medical care continuity and patient mortality: a systematic review. $\mathrm{Br} J$ Gen Pract 2020;70:e600-11.

14 Nyweide DJ, Bynum JPW. Relationship between continuity of ambulatory care and risk of emergency department episodes among older adults. Ann Emerg Med 2017;69:407-15.

15 Nyweide DJ, Anthony DL, Bynum JPW, et al. Continuity of care and the risk of preventable hospitalization in older adults. JAMA Intern Med 2013;173:1879-85.

16 Kaye HS. Disability-related disparities in access to health care before (2008-2010) and after (2015-2017) the Affordable Care Act. Am J Public Health 2019;109:1015-21.

17 Bailey ZD, Krieger N, Agénor M, et al. Structural racism and health inequities in the USA: evidence and interventions. Lancet 2017:389:1453-63.

18 American Diabetes Association. 6. Glycemic Targets: Standards of Medical Care in Diabetes-2020. Diabetes Care 2020;43:S66-76.

19 American Diabetes Association. 11. Microvascular Complications and Foot Care: Standards of Medical Care in Diabetes-2020. Diabetes Care 2020;43:S135-51.

20 American Diabetes Association. 1. Improving Care and Promoting Health in Populations: Standards of Medical Care in Diabetes-2020. Diabetes Care 2020;43:S7-13.

21 Zhang X, Bullard KM, Gregg EW, et al. Access to health care and control of ABCs of diabetes. Diabetes Care 2012;35:1566-71.

22 Schectman JM, Schorling JB, Voss JD. Appointment adherence and disparities in outcomes among patients with diabetes. J Gen Intern Med 2008;23:1685-7.

23 Parchman ML, Pugh JA, Noël PH, et al. Continuity of care, selfmanagement behaviors, and glucose control in patients with type 2 diabetes. Med Care 2002;40:137-44.

24 Maciejewski ML, Hammill BG, Bayliss EA, et al. Prescriber continuity and disease control of older adults. Med Care 2017;55:405-10.

25 Ward MM. Access to care and the incidence of end-stage renal disease due to diabetes. Diabetes Care 2009;32:1032-6.

26 Canedo JR, Miller ST, Schlundt D, et al. Racial/ethnic disparities in diabetes quality of care: the role of healthcare access and socioeconomic status. J Racial Ethn Health Disparities 2018:5:7-14.

27 Medicaid.gov. Health Homes [Internet]. Available: https://www. medicaid.gov/medicaid/long-term-services-supports/health-homes/ index.html [Accessed 21 Sep 2020].

28 Patchias EM, Detty A, Birnbaum M. Implementing Medicaid Health Homes in New York: early experience. Medicaid Institute at United Hospital Fund, 2013. Available: http://www.uhfnyc.org/publications/ 880881 [Accessed 20 Feb 2015].

29 New York State Department of Health. New York State Medicaid Update: New York State Medicaid Health Homes. [Internet]. Available: http://www.medicaid.gov/state-resource-center/medicaidstate-technical-assistance/health-homes-technical-assistance/ downloads/medicaid-health-homes-overview.pdf [Accessed $15 \mathrm{Mar}$ 2015].

30 Mayer VL, Siscovick D, Goytia C, et al. "Not Alone Anymore": The Experiences of Adults With Diabetes in New York's Medicaid Health Home Program. Med Care 2020;58 Suppl 6 Suppl 1:S60-5.

31 Kaushal R, Hripcsak G, Ascheim DD, et al. Changing the research landscape: the New York City Clinical Data Research Network. J Am Med Inform Assoc 2014;21:587-90.

32 Nichols GA, Desai J, Elston Lafata J, et al. Construction of a multisite Datalink using electronic health records for the identification, surveillance, prevention, and management of diabetes mellitus: the SUPREME-DM project. Prev Chronic Dis 2012;9:110311.

33 Agency for Healthcare Research and Quality, Healthcare Cost and Utilization Project. Clinical Classifications Software (CCS) for ICD-9-CM [Internet]. Available: https://www.hcup-us.ahrq.gov/ toolssoftware/ccs/ccs.jsp [Accessed 21 Sep 2020]. 
34 Agency for Healthcare Research and Quality, Healthcare Cost and Utilization Project. Chronic Condition Indicator [Internet]. Available: https://www.hcup-us.ahrq.gov/toolssoftware/chronic/chronic.jsp [Accessed 21 Sep 2020].

35 Pollack CE, Hussey PS, Rudin RS, et al. Measuring care continuity: a comparison of claims-based methods. Med Care 2016;54:e30-4.

36 Hussey PS, Schneider EC, Rudin RS, et al. Continuity and the costs of care for chronic disease. JAMA Intern Med 2014;174:742-8.

37 Huber M, Lechner M, Steinmayr A. Radius matching on the propensity score with bias adjustment: tuning parameters and finite sample behaviour. Empir Econ 2015;49:1-31.

38 Hainmueller J. Entropy balancing for causal effects: a multivariate reweighting method to produce balanced samples in observational studies. Political Analysis 2012;20:25-46.

39 Daw JR, Hatfield LA. Matching and regression to the mean in Difference-in-Differences analysis. Health Serv Res 2018;53:4138-56.

40 Jacob Cohen. Statistical power analysis for the behavioral sciences. 2nd edn. Routledge, 1988.

41 Polanin JR, Snilstveit B. Converting between effect sizes. Campbell Syst Rev 2016;12:1-13.

42 Joo JY, Huber DL. Case management effectiveness on health care utilization outcomes: a systematic review of reviews. West $J$ Nurs Res 2019;41:111-33.

43 Brown RS, Peikes D, Peterson G, et al. Six features of Medicare coordinated care demonstration programs that cut hospital admissions of high-risk patients. Health Aff 2012;31:1156-66.

44 McCarthy D, Ryan J, Klein S. Models of Care for High-Need, HighCost Patients: An Evidence Synthesis [Internet]. The Commonwealth Fund:, 2015. Available: https://www.commonwealthfund.org/ publications/issue-briefs/2015/oct/models-care-high-need-highcost-patients-evidence-synthesis [Accessed 10 Sep 2020].

45 Peikes D, Chen A, Schore J, et al. Effects of care coordination on hospitalization, quality of care, and health care expenditures among Medicare beneficiaries: 15 randomized trials. JAMA 2009;301:603-18.

46 Hudon C, Chouinard M-C, Lambert M, et al. Effectiveness of case management interventions for frequent users of healthcare services: a scoping review. BMJ Open 2016;6:e012353.

47 Stokes J, Panagioti M, Alam R, et al. Effectiveness of Case Management for 'At Risk' Patients in Primary Care: A Systematic Review and Meta-Analysis. PLoS One 2015;10:e0132340.

48 Baker JM, Grant RW, Gopalan A. A systematic review of care management interventions targeting multimorbidity and high care utilization. BMC Health Serv Res 2018;18:65.

49 Buja A, Francesconi P, Bellini I, et al. Health and health service usage outcomes of case management for patients with longterm conditions: a review of reviews. Prim Health Care Res Dev 2020;21:e26.

50 Michalopoulos C, Manno MS, Mijanovich T. Final Report on an Evaluation of Six Pilot Coordinated Care Projects for High-Needs Medicaid Recipients [Internet]. MDRC, 2014. Available: https:// www.mdrc.org/publication/final-report-evaluation-six-pilotcoordinated-care-projects-high-needs-medicaid [Accessed 10 Sep 2020].

51 Brown AF, Ettner SL, Piette J, et al. Socioeconomic position and health among persons with diabetes mellitus: a conceptual framework and review of the literature. Epidemiol Rev 2004;26:63-77.

52 Goldberg RW, Kreyenbuhl JA, Medoff DR, et al. Quality of diabetes care among adults with serious mental illness. PS 2007;58:536-43.

53 Druss BG, Zhao L, Cummings JR, et al. Mental comorbidity and quality of diabetes care under Medicaid: a 50-state analysis. Med Care 2012;50:428-33.

54 Mangurian C, Newcomer JW, Modlin C, et al. Diabetes and cardiovascular care among people with severe mental illness: a literature review. J Gen Intern Med 2016;31:1083-91. 